\title{
Animal farm: pig in the middle
}

\author{
The 2009 flu pandemic highlights the urgent need for an independent international body for research into \\ human diseases that originate in animals.
}

W hen animal pathogens make the leap into humans - as has happened with the 2009 pandemic virus that originated in swine - animal-health scientists can find themselves in an awkward position. Unlike their colleagues in public health, who focus their energies on protecting the planet's 6.8 billion humans, animal-health specialists tend to work through government agencies, whose primary mission is to promote and protect national and international livestock and meat trade.

This focus on commerce can sometimes lead to conflicts of interest, as well as some policy positions that border on denial. Since the first outbreaks of the 2009 pandemic virus in the United States and Mexico, for example, the Paris-based World Organisation for Animal Health (OIE) has expended considerable energy trying to keep people from calling the virus 'swine flu'. The OIE's quite legitimate concern is that this nomenclature might adversely affect trade, with countries taking unnecessary measures such as culling herds, or invoking trade bans on pigs and pork. From a strictly scientific point of view, however, there is abundant genetic evidence that the name is appropriate. It is a reassorted swine influenza virus that has jumped from pigs to humans.

The OIE has also played down the possibility that the 2009 pandemic flu might be spreading in pigs, noting that it has not been found in any animals outside of one farm in Canada. But how vigorous has the search been? There is no requirement that the authorities be notified of flu in pigs, as the animals generally recover, and farmers have little incentive to report an outbreak in their herds given the potential repercussions. Furthermore, little funding has been available for extensive surveillance. A case in point is the European Surveillance Network for Influenza in Pigs, whose paltry $€ 100,000$ (US\$139,000) in annual funding expired in March, just a month before the pandemic

strain was first detected. Yet public-health researchers say that if the virus is circulating in pigs, and moving back and forth between pigs and humans, it increases the risk that the virus will genetically reassort into a more dangerous pathogen (see page 894).

The human-animal disease interface is fraught with such competing agendas. But to the OIE's credit, it has had a key role in creating a body that could be a model for a credible, honest broker. Founded jointly with the United Nations' Food and Agriculture Organization (FAO) in 2005, the OIE/FAO Network of Expertise on Animal Influenza (OFFLU) has been bringing together labs working on surveillance and research of human infectious diseases that have arisen in animals. OFFLU has also been outspoken on the

"Surveillance of
human diseases
that originate in
animals remains
in the nineteenth
century."
need for countries to share virus samples and sequences for research (see Nature 440, 255-256; 2006) and has built important bridges with the World Health Organization (WHO) and other public-health agencies.

What is needed now is international support for a greatly expanded OFFLU-like network that has enough funding to do its own research and to coordinate global surveillance efforts on influenza and other diseases emerging from animals. The WHO and other public-health organizations should also be made an integral part of the network.

The 2009 pandemic has forced scientists to confront the elephant - or pig - in the room, which is that surveillance of human diseases that originate in animals remains in the nineteenth century (see Nature 440, 6-7; 2006), and is chronically underfunded. Animaland public-health bodies must now step up and fund a serious joint initiative in this area.

\section{Coherent advocacy please}

\section{Reactions to UK government changes are an example of how researchers should not behave in a downturn.}

A s high-energy physicists and astronomers learned long ago, when making the case for investments in science it is helpful or even essential to present a coherent front to outsiders, not least governments. The idea that the entirety of scientific research could present such a united front in public will strike most of Nature's readers as fanciful. Yet some coherence will be needed in the months and years ahead if science is to maintain the public support it needs, at a time when severe economic and other challenges assail scientifically active countries.

Most politicians appreciate the bounties of science; for example, drugs now entering clinical trials that are direct outcomes of basic biomedical research, and experimental revelations about the Universe and human origins. But they do not necessarily understand the process of science - the unpredictabilities of fundamental research, the uncertainties in applying that research to real problems, and the sheer scale of effort required to make headway.

In straitened times, the politicians within any government or legislature who do understand the importance of science need all the help they can get from the research community as they seek to maintain its financial support. How scientists should not react in such an environment has been well illustrated over the past two weeks in the United Kingdom. The Labour government, weakened by resignations and recent election losses, instituted a reshuffle of ministers and ministries that moved funding for science and universities away from a dedicated department created two years ago and into the new Department for Business, Innovation and Skills. Immediately there 